\title{
A holistic assessment of the impacts of park management: findings from the evalu- ation of Regional Nature Parks in Switzerland
}

\author{
Thomas Hammer, Roger Bär, Albrecht Ehrensperger, Andreas Friedli, Karina Liechti, Astrid Wallner \& Thea \\ Xenia Wiesli
}

Keywords: management effectiveness, evaluation of parks and large-scale protected areas, Regional Nature Parks, Switzerland

\section{Abstract}

In Switzerland, Regional Nature Parks are required to undergo an impact assessment after ten years of operation, in order for the federal government to award the Park of National Importance label for a further ten years and for the government, relevant canton and communes to continue to provide financial support for the park's operation. To this end, is there a convenient way of identifying and holistically assessing the impacts of park management activities on the goals of the parks and the overarching targets of parks policy in Switzerland?

Based on experience gained from the evaluation of three Regional Nature Parks, we have developed a framework model for the holistic evaluation of such parks and present it here for discussion.
Profile

Protected area

Regional Nature Parks

Chasseral, Diemtigtal

and Gantrisch

Mountain range

Alps, Switzerland

\section{Introduction}

A broad discussion of how to measure the effectiveness of park management can be found with reference to the keywords Protected Area Management Effectiveness (PAME) (Coad et al. 2015; Ferreira et al. 2018; Hockings et al. 2006, 2015; Leverington et al. 2010a, 2010b, 2010c; Nolte et al. 2010; Oldekop et al. 2014). The discussion began with the implementation of the Convention on Biological Diversity (CBD) and initially focused on the question of how to determine the effects of measures aimed at protecting biodiversity and achieving the goals of the Convention (Coad et al. 2015). The spotlight also fell initially on issues related to improving management processes (for example, involving local actors). The international conversation widened to include the question of how to measure management impacts for UNESCO Biosphere Reserves (Ferreira et al. 2018), prompted by the fact that Biosphere Reserves, unlike strict protected areas, play a role in socio-economic development as well as conservation. With the ongoing debate on sustainable development and the emerging view that many protected areas offer multiple socio-economic and cultural benefits for the region in addition to their ecological contribution, it is now widely recognized that management impacts also need to be considered and assessed with the bigger picture in mind (Hockings et al. 2015). The discussion has turned to how the impacts of protected areas can be measured holistically, for example from a sustainable development perspective (Ferraro \& Hanauer 2015; Ferraro \& Pressey 2015).

The discussions reflect the fact that parks are usually confronted with multiple - often very diverse
- economic and social expectations on the part of local stakeholders, even if the parks belong to the same IUCN category (Hammer et al. 2016). In Switzerland, Regional Nature Parks (RNPs) must undergo an impact assessment at the end of a ten-year operating phase in order to apply for renewal of the Park of National Importance label and a subsequent ten-year operating phase (Swiss Parks Network 2021). A key question in this respect is how to assess the impacts of park management activities holistically, i.e. in relation to the overall objectives and those of the parks policy, in a manner commensurate with the means available (Plachter et al. 2012; Ferraro \& Hanauer 2015; Ferraro \& Pressey 2015).

The aim of this paper is to construct and justify a framework model for the holistic evaluation of a specific type of Swiss park, namely RNPs, based on experience evaluating the impacts of management activities at three parks. The framework model is intended to be used to design impact assessments for this and similar types of park, to derive relevant questions and to frame the results.

The model is based on our experience evaluating the three RNPs in the canton of Bern: Chasseral, Diemtigtal and Gantrisch (see Figure 1). These three parks were selected because the Canton of Bern decided to evaluate them together instead of individually and to develop an appropriate method for this purpose. In this paper we present, in turn, the Swiss concept of RNPs, the evaluation design, the results of the evaluation and lessons for the holistic evaluation of RNPs in Switzerland. We then explain the framework model and formulate conclusions. 


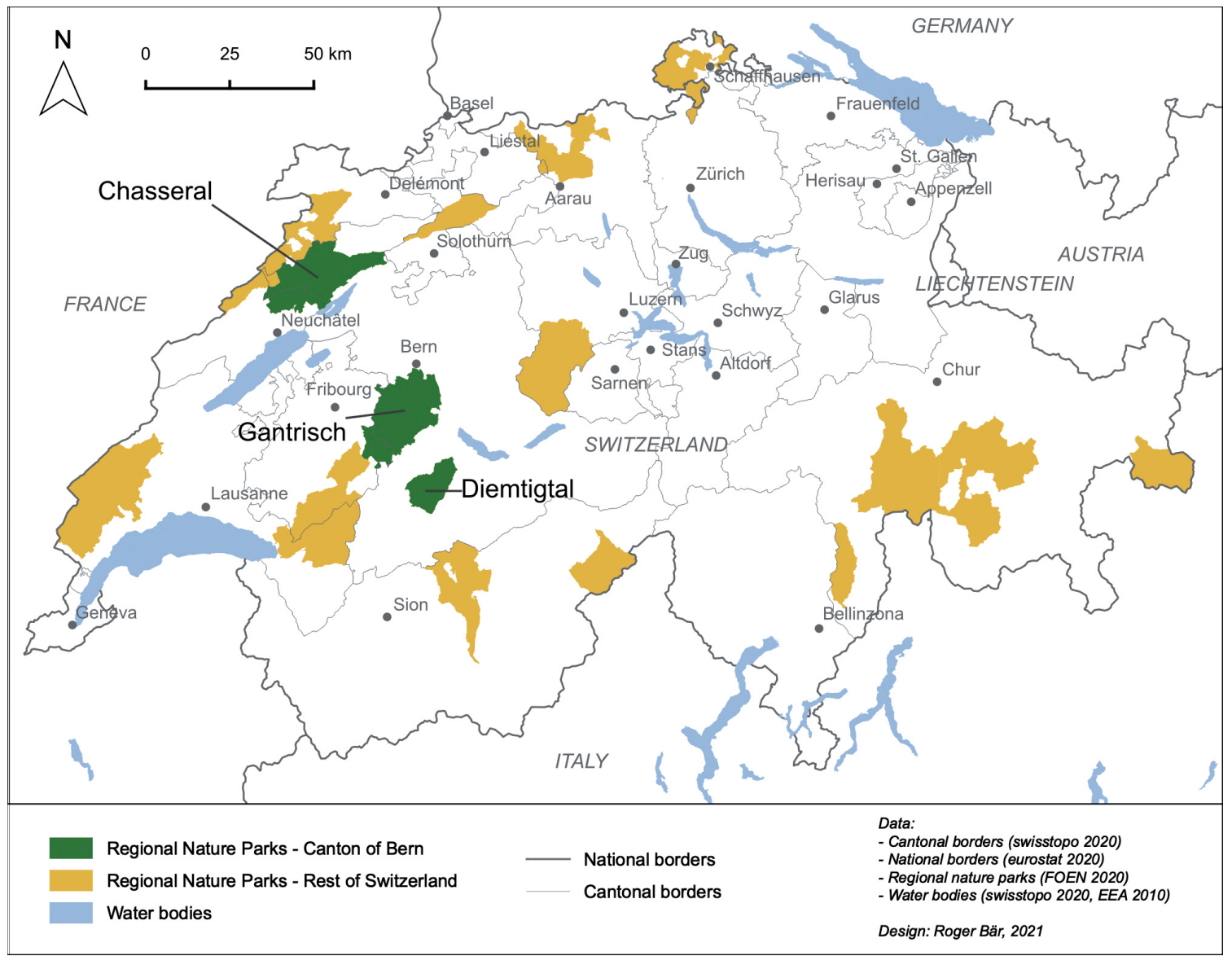

Figure 1 - Regional Nature Parks in the canton of Bern (green) and in the rest of Switzerland (yellow).

\section{The Swiss concept of Regional Nature Parks}

Legislation governing RNPs and the cantons concerned is laid down in the Federal Act on the Protection of Nature and Cultural Heritage (NCHA) and in the Parks Ordinance (ParkO) (Federal Assembly of the Swiss Confederation 1966 / 2020; Swiss Federal Council 2007 / 2018). Table 1 summarizes the main requirements contained in the legislation in relation to park areas and the establishment and operation of the parks. These include obligations relating to minimum size, quality of natural and cultural environments, spatial planning safeguards, participation of local residents, companies and organizations in the establishment and management of the park, composition and organization of the park authority, the role of the responsible cantons and the goals to be pursued. The main features of the Swiss concept of RNPs are as follows:

- A RNP is usually composed of several communes. The communes involved in the park set up a park authority on which they are represented and have a majority of the votes.

- In close consultation with the canton, the park authority draws up a ten-year charter on the operation and quality assurance of the parks. The charter contains the strategic goals and a management plan for the ten years and serves as the park authority's strategic steering instrument.
- To implement the charter, the park authority and the canton, in consultation with the federal government, draw up a four-year programme agreement. This agreement specifies, among other things, which projects are to be implemented and how funds are to be used; it lays out the proportions in which the communes, relevant canton(s), federal government and other actors will contribute financially and with other services.

- The park authority appoints a park management body which is responsible for the operational implementation of the strategic goals and the programme agreement.

- To apply for recognition and support from the federal government, the park communes have to demonstrate that the majority of the population living in the park supports the establishment of a park.

- If the federal government approves the application for recognition as a RNP, it awards the Park of National Importance label to the park authority for a period of ten years.

The Swiss concept of RNPs is characterized by the need to demonstrate the local population's approval for the establishment of a RNP.

The Park of National Importance label belongs to the park authority and thus to the park communes. The communes pursue strategic goals, which are imple- 
Table 1 - Legislation governing the Regional Nature Parks (RNPs) in Switzerland (NCHA Art. 23g; Park. Art. 15, 19-21, 25-28).

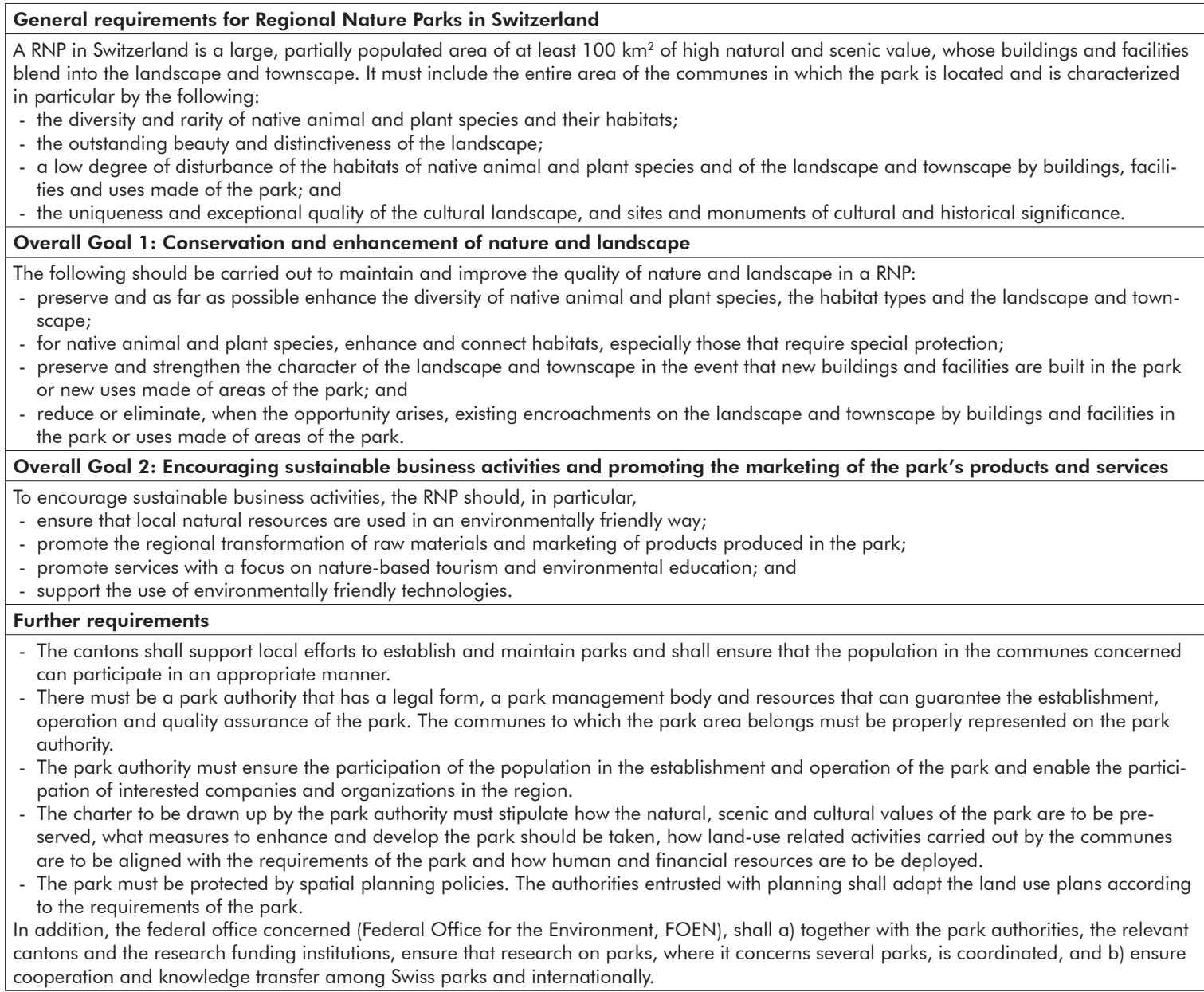

mented on the ground by a park management body. The park management body itself has no legislative powers. This has implications for a holistic assessment of management impacts: in addition to the legislative requirements at national and cantonal levels, the expectations of the local population and other stakeholders must also be taken into account. Some stakeholders (not just in Switzerland), for example, regard nature parks as model regions of sustainable development and have corresponding demands that go beyond the legal requirements (Dinica 2016; Hammer et al. 2018; Romagosa et al. 2015).

The Canton of Bern and the park authorities provided financial resources for the evaluation, but these were limited, so it was not possible to conduct wideranging, comprehensive research. In order to measure - or at least estimate - the impacts of park management activities, we therefore had to develop an approach that was commensurate with the means available.

\section{Evaluation design}

The federal government provides guidelines for the evaluation of Parks of National Importance (FOEN 2014 / 2019). According to the guidelines, three analy- ses are to be carried out. Firstly, an analysis should be conducted showing what significant changes (e.g. social, political) have taken place in and around the park since the start of the operating phase and what implications these changes have had in relation to park management. Secondly, it should be determined to what extent the legally prescribed overarching goals and the strategic goals formulated by the park have been achieved. And thirdly, an overall assessment of the management effectiveness should be carried out, which will also demonstrate the implications for the future direction of the charter and park management activities.

The evaluation of the three RNPs in the canton of Bern (mid-2018 to end of 2019; Bär et al. 2020) was based on these guidelines and, as far as possible, designed as a transdisciplinary research project. Scientific responsibility lay with the Centre for Development and Environment (CDE) of the University of Bern. An advisory group consisted of representatives of the Canton, the three RNPs, the Swiss Park Research Coordination Office and a private consultancy. Their task was to provide constructive criticism and guidance in relation to the planning, implementation and analysis of the evaluation. 
Table 2 - Example of the operationalization of the legally prescribed overall goal Conservation and enhancement of nature and landscap by one of the three Regional Nature Parks in the form of a strategic goal and several outcome and output goals.

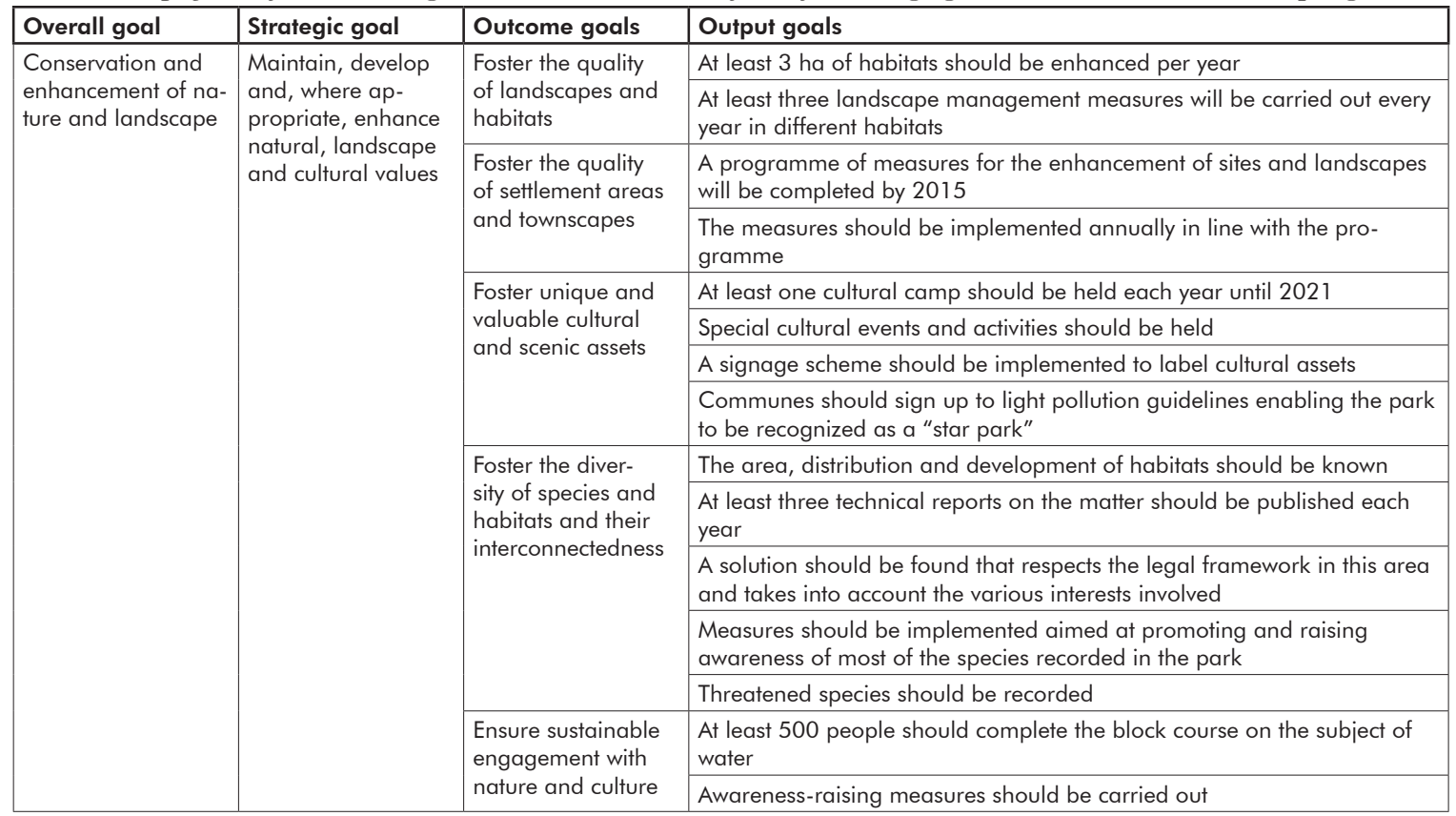

The evaluation design was based on the standard model of policy evaluation, as advocated by the International Union for Conservation of Nature (IUCN) (Hockings et al. 2015, p. 900-902) and as used, in a modified form, by the Swiss Federal Office for the Environment (FOEN) as a framework for evaluation (see Figure 2). This model essentially distinguishes between the following four elements: inputs (available resources), processes (implementation in the form of activities and measures), outputs (services and products provided) and outcomes (results and impacts).

Our methodological design made it possible to identify outputs and outcomes and to assess related objectives based on criteria and indicators. Where possible, we derived the criteria and indicators from the objectives and other specifications set out in the respective management plans of the three parks. However, indicators could only be determined for two parks, because one of the three management plans contained almost no quantitative targets. In this case, the criteria alone were used to assess the outputs and outcomes. As the three parks operationalized the overarching goals for all parks in different ways, we had to define specific criteria and indicators for each park to assess their outputs and outcomes. Table 2 shows an example of how a park has operationalized an overarching goal.

The evaluation was also designed to take into account specific characteristics of each park. We therefore analysed existing data and previous studies relating to the nature parks and carried out park-specific surveys, interviews with local actors and workshops.
Evaluation results and lessons for the holistic evaluation of Regional Nature Parks in Switzerland

The results of the evaluation of the three RNPs in the canton of Bern have been published in a synthesis report (Bär et al. 2020). These can be summarized as follows: Across all three parks, about two thirds of the output and outcome goals were achieved or even surpassed. The remaining objectives were achieved only partially or not at all, for various reasons, or no reliable statements could be made on their achievement. The park management body succeeded in implementing a range of measures and projects that had positive impacts.

Overall, we found that park management bodies' options for action were, in line with the resources available to them, severely limited in regard to the strategic goals formulated by the respective park authorities to achieve the goals specified in the legislation, and the very wide-ranging, and in part contradictory, social demands. Park management can contribute to gradual changes by cooperating closely with local and regional actors and by informing, raising awareness, initiating, advising, motivating, networking and providing support. Park management can also create incentives for action, such as awarding its own certification label for products produced in the park that meet certain standards, organizing competitions or offering attractive opportunities for volunteers. But what park management can effectively achieve depends very much on local circumstances such as local authorities, local policies, the existence of various local and regional actors and their willingness to cooperate, and the funding available. 


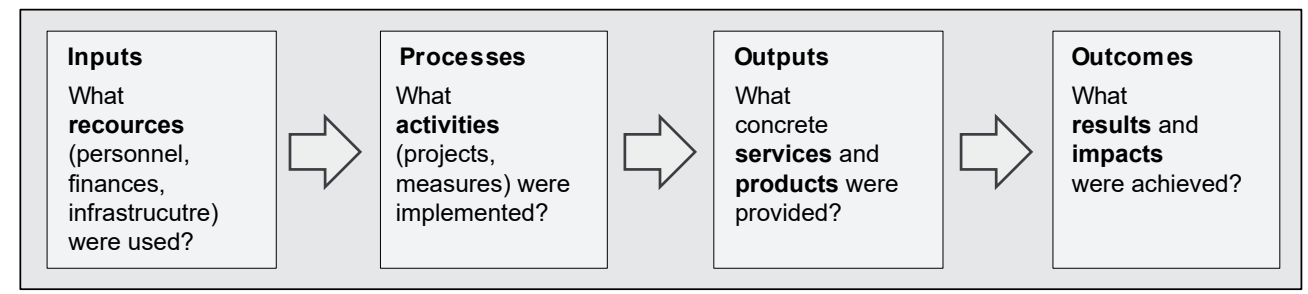

Figure 2 - Standard model for the evaluation of the impact of management activities on parks (adapted from Hockings et al. 2015, p. 901).

The evaluation of the three RNPs in the canton of Bern showed that a rule-book approach quickly reaches its limits. Regional complexity and the ten-year operating phase form a dynamic monitoring context which a static approach is not well-suited to reflect. In order to identify the main lessons learned, we examined the experiences associated with the evaluation of the three RNPs in a working session. In this session, we were able to refer to various discussions held during the evaluation process. The findings from the six workshops (two workshops per park) held to assess the output and outcome goals with the park management bodies and other local actors proved to be particularly valuable. In particular, the following insights were gained and challenges identified:

\section{The evaluation is a learning process}

During the evaluation, we found that the actors involved in the process discussed issues and gained insights; these can be interpreted as learning processes and are thus relevant for both park management and research purposes. Assessing the impact of park management activities in the way we have done is therefore an integrated transdisciplinary research and learning process that differs substantially from, for example, clearly delineated evaluation formats such as evaluation research, self-evaluation and external evaluation, while at the same time combining the strengths of these approaches. Throughout the process, the three park management bodies, researchers, one representative from each of the Canton of Bern, Park Research Switzerland and a non-governmental organization, and other local stakeholders participated in the six workshops in the three RNPs. Involving a wide range of actors in this manner provides differentiated knowledge of the context, enables adaptation of the evaluation to local conditions and leverages knowledge of the park management body's scope of action.

\section{A differentiated methodological design is needed for the evaluation}

Identifying and assessing outputs and outcomes is demanding. The assessment cannot be designed solely in relation to resources and process. Contextual factors such as communal, cantonal and national policies, and the park management body's scope of action, are essential to reduce attribution gaps in explaining the causal relationship between the resources, process fac- tors, outputs and outcomes. In addition, not all output and outcome objectives, criteria and indicators were adequately formulated at the beginning of the ten-year operating phase, so that it was not sufficient to consider only the criteria and indicators originally defined.

\section{Some developments are difficult to observe and identify}

Various developments such as changes in biodiversity and landscape and the effects of awareness-raising and educational measures are difficult to determine and quantify. Although we came to the conclusion that park management activities make significant contributions to achieving outcome goals, this does not necessarily mean that the environmental, social and economic situation in the Bernese Nature Parks improved in all relevant areas during the operating phase.

\section{Adaptive management is systemic}

RNPs contribute to developments that are significant from a sustainability perspective but were not originally planned in the charter. These include, for example, contributions to strengthening regional cooperation and regional identity. In a dynamic region, a nature park must be able to respond to changing social demands. Simply ticking off previously formulated output and outcome goals and indicators does not do justice to circumstances on the ground.

Aspects of process design must be included in the evaluation

Governance structures that enable local and regional actors to take initiative and participate are essential for the success of a RNP. On the whole, RNPs are soft steering instruments of sustainable development with limited capability and means. However, they can indirectly influence the ongoing development of hard underlying institutional aspects (e.g. spatial planning), and thus prepare the ground for substantial changes towards sustainability.

A framework model for the holistic assessment of Regional Nature Parks in Switzerland

Based on the lessons learned from the evaluation of the three Regional Natural Parks in the canton of Bern, we propose a differentiated framework model 


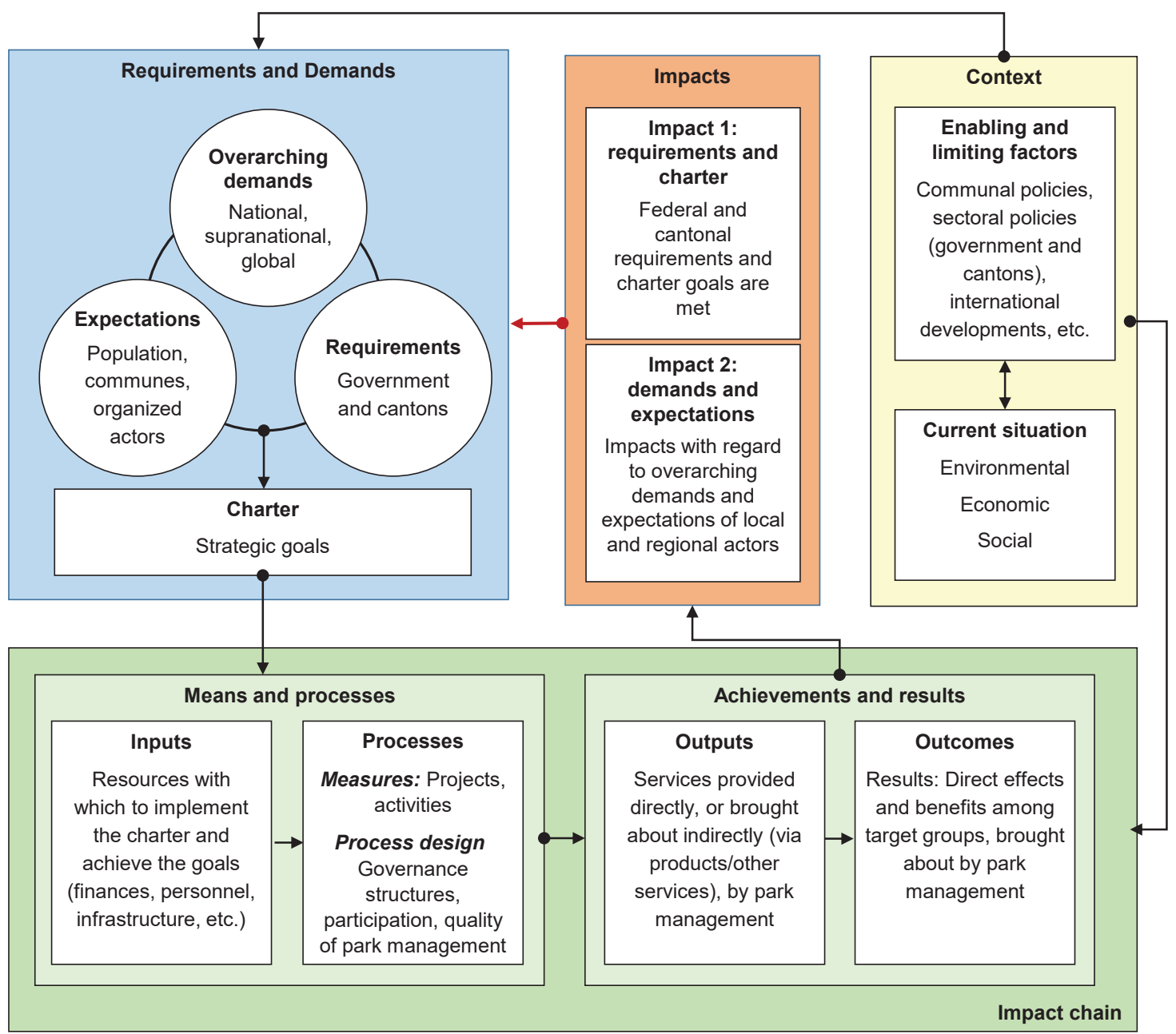

Figure 3 - Model for evaluating the impacts of management on Regional Nature Parks in Switzerland: The blue box shows the requirements and demands. These are composed firstly of the general national and international expectations of protected areas (e.g. contribution to the conservation of biodiversity), which are not necessarily laid down in law (e.g. contribution to combating climate change and to the energy transition). Secondly, these and possibly other expectations are specified in national and cantonal legal provisions (requirements). Thirdly, the local population and other local actors have expectations of the parks, which are all incorporated into the charter as a normative framework, for park management. The charter in turn provides the framework for the means and processes (arrow from blue to green box) that are part of the standard model (inputs, processes, outputs, outcomes) shown in Figure 2 (green box). The inputs and processes determine which outputs and outcomes are produced. The context (yellow box) also has a significant bearing (arrow from yellow to green box) on these outputs and outcomes. The outputs and outcomes have effects (arrow from the green to the orange box) on the context and the requirements and demands (arrows in red). The effects on the context also feed into changes in the requirements and demands (arrow from the yellow to the blue box).

for the holistic assessment of RNPs in Switzerland (see Figure 3). This model is intended to encourage consideration of all essential elements right from the initial development of an evaluation, to help us think about them in a networked way and to enable the corresponding evaluation questions to be formulated (see Table 3). Compared to the standard model shown in Figure 2, it demonstrates significant refinements:

First, the proposed framework model places much greater importance on processes (second element in the standard model in Figure 2 and second element in the impact chain in Figure 3) by giving strong weight to process design in addition to measures. What park management can achieve depends largely on what governance structures are in place, how local and re- gional actors are involved and can participate, and the quality of park management. It therefore makes sense, in addition to the actual projects and other activities, to relate the process design in particular to the outputs and outcomes in the area of implementation and also to assess the process design itself.

Second, the extended framework model presents outcomes in a more differentiated way. Whereas in the standard model (see Figure 2) results and impacts are considered together, the extended model (Figure 3) divides them into direct effects (direct effects and benefits among target groups brought about by park management, described in Figure 3 as outcomes and broader-ranging effects (described in Figure 3 as impacts). 
Table 3 - Example of a questionnaire for evaluating the impacts of management activities on Regional Nature Parks in Switzerland. Questions about the services provided ("Outputs") and the results achieved ("Outcomes")

What outputs are provided directly by park management activities and what outputs are brought about indirectly with the help of projects and activities (e.g. products, services)? Have the output goals been met?

What are the direct effects brought about in the target groups and target assets (including in relation to land use, landscape and nature?

Have the outcome goals been met?

If the output and/or outcome goals were not met, what are the reasons for this?

Were the output and outcome goals commensurate with the resources available?

How have contextual factors such as communal policies, cantonal and federal sectoral policies, and international developments influenced outputs and outcomes?

Questions about the impacts (Impacts 1 and 2)

To what extent have the federal and cantonal requirements been met and the strategic goals set out in the charter achieved? (Impact 1) Have adequate contributions been made to fulfilling overarching national, international and global demands (e.g. to mitigating climate change) and to fulfilling local expectations (e.g. preservation of jobs)? (Impact 2)

If federal and cantonal requirements and the goals set out in the charter have not been met: What are the reasons for this? What influence did contextual factors have?

What are the main changes in the park area in environmental, economic and social terms that have resulted from all outputs, outcomes and impacts of park management? (Impacts on the current situation)

Questions about the use of resources and the implementation process

Have the available resources (including finances, personnel, infrastructure) been used appropriately and in line with the strategic goals se out in the charter?

Did the measures implemented (e.g. projects, activities) achieve the intended outputs and outcomes? Were the measures adequate and appropriate to achieve the outputs and outcomes?

Have appropriate governance structures been established for the implementation of the measures and have appropriate participation processes been designed? Have the measures been accompanied by an adequate quality of park management?

Questions about refinements to the charter and the federal and cantonal requirements based on the evaluation results

What need is there to adapt the strategic goals in light of current and expected overarching demands, expectations of local actors and requirements of the federal government and the canton?

What are the recommendations regarding future measures, process design and the use of resources to achieve the strategic goals?

What are the recommendations regarding the ongoing development of federal and cantonal requirements?

Third, the extended model supplements the standard model by providing a coherent framework that includes both the context and the requirements and demands. This consists of: (a) feedback loops (Impacts in the orange box and red arrows, Figure 3), through which the outputs and outcomes influence the requirements and demands (blue box) and the context (yellow box) via their impacts and thus continuously reshape the evaluation framework; and (b) requirements and demands at different levels (blue box). Through their interplay, these elements form a dynamic framework, the understanding of which is indispensable for a contextual evaluation that leads to helpful recommendations. The importance of these elements for an evaluation is described below:

\section{Feedback loops}

These are at the heart of the framework model, as they reveal changes in the park's context and the expectations of the actors in that context (and beyond); these feedback loops should therefore be seen as part of the context rather than as an external construct. This subtlety is essential because it implies that a dynamic goal is an integral part of the context and that this requires park management to be adaptive.

\section{Impacts}

The impacts represent the changes achieved. Capturing them is key, since an evaluation is concerned particularly with identifying and assessing the actual changes achieved. Here we distinguish on the one hand between impacts that relate to requirements and demands, i. e. those that concern, among other things, the requirements of the federal government and the canton, the expectations of the population and other actors, and the goals set out in the charter (blue box, Figure 3). On the other hand, we distinguish between impacts on the context (yellow box), such as changes brought about by enabling and limiting factors, and changes in the sustainability dimensions of environment, economy and society. The elements distinguished in the blue and yellow boxes are intended to help classify the changes identified.

The same applies to the elements distinguished in the Impacts box. In principle, it makes sense on the one hand to identify the impacts in terms of the federal and cantonal requirements and the charter objectives (orange box, Figure 3: Impact 1: requirements and charter), which is a crucial part of evaluating a RNP. However, as explained above, the parks face further demands from a national, supranational and global perspective and expectations of local and regional actors, which is why it makes sense to also identify impacts related to the role of RNPs as model regions for sustainable development. In the case of the latter, questions should also be asked about the soft effects, such as changes in regional identity, in sustainability awareness or in forms of cooperation, which are difficult to identify but are of fundamental importance for sustainable development. Central to the understanding of the framework model and the design of evaluations is that Impacts 1 and 2 generate an effect with regard to the ongoing development of the charter, the requirements of the federal government and the relevant canton, the contextual conditions, the expectations of local and regional actors, and the overarching demands on RNPs: 


\section{Expectations and requirements}

These shape the content of the charter at the start of the operating period (see below). It is therefore necessary when formulating the charter to consider which overarching societal effects (Impact 2, e.g. energy transition, reduction of the use of natural resources, increase in the quality of life, sustainable mobility) are to be achieved through the measures aimed at achieving the strategic goals in the park area (Impact 1). For the evaluation, however, this also means that expectations and requirements are to be understood as dynamic elements, as became evident in the evaluation of the Bernese Parks: the priorities that were set out in the charter had changed ten years later. For example, adaptation to climate change, which may have been viewed with scepticism ten years ago, is now much more important, be it for winter tourism or for agriculture.

\section{Context-specific factors}

As the consideration of contextual factors is essential for an appropriate assessment of management effects, these take on a framing function in the model. Two types of factor can be distinguished in this respect: first, the region's current situation (environmental, economic, social) and second, the enabling and limiting factors. The contextual factors influence the overarching demands on RNPs, the requirements of government and canton, and the expectations of local and regional actors and thus the formulation of the charter. They also influence the inputs, implementation process, outputs and outcomes, and thus, indirectly, the impacts. The impacts in turn lead to changes in the context, and the altered context consequently influences the demands, expectations and requirements, which in turn influence the inputs and the implementation process.

\section{Strategic goals}

Finally, the strategic goals set out in the charter are based on the requirements of the federal government and the relevant canton, and the expectations of local and regional actors. The services provided to the park management body and their strategic use are also described in the charter. These services also represent the inputs that are available to the park management body for the operational implementation of the charter. In the context of an evaluation, the temporal context in which these goals were formulated must not be forgotten, and the difference between priorities at the time the goals were set, intermediate priorities and priorities at the time of evaluation (for example, changes in priority that arise due to a change in legislation) must be taken into account.

\section{Discussion}

Using the extended framework model for an evaluation takes greater effort than using the standard model. The extended model requires a consistent immersion in the context of the relevant park; it is more than a matter of checking off indicators and quantifying outputs and outcomes. It places high demands on everyone involved, especially researchers. They must be able to enter into a process with an uncertain outcome, integrate the perspectives of all actors and maintain high scientific standards.

On the other hand, such an evaluation also offers significant added value, namely the design and implementation of a joint learning process which can support the region as a whole in its transformation towards sustainability. The evaluation can demonstrate which lessons can be learned from the implementation process up to that point - to what extent park management has contributed to fulfilling the requirements set out in the charter, to achieving the strategic goals (Impact 1) and the overarching societal demands (Impact 2) - and what its future contributions should be. We believe that carrying out an evaluation based on the proposed framework model serves as a learning tool for the park management and the other actors involved in the evaluation of the relevant park which makes it possible to deal with fundamental questions that go well beyond the minimum evaluation results required by the authorities.

It is essential that this process is participatory. For without the broad involvement of local actors, there is no opportunity to engage in a joint learning process. In the evaluation of the three Bernese Nature Parks, it would have been useful to involve the local population and other stakeholders more extensively, for example in discussions on the future role of a RNP and the scope of action granted to the park management body, especially with a view to creating a good basis for taking the charter forward.

Based on experience gained from the evaluation, we can conclude that understanding the evaluation of the charter as a comprehensive learning tool enables park authorities and park management to engage in a process with the local actors, take a critical look back at previous activities and develop forward-looking visions for sustainable development in the region.

We consider the creation of a differentiated hierarchy of objectives with corresponding criteria and indicators along the impact chain of outputs, outcomes and impacts to be a useful guide both for park management and for carrying out an evaluation. Impact 2 (desired impacts with regard to overarching demands and expectations of local and regional actors) can reflect, in particular, how park management wants to contribute to overarching social sustainability goals beyond the immediate strategic goals of the RNP, i.e. to goals that are not included in the core mission, but that various actors expect RNPs to fulfil as models of sustainable development. It is important that appropriate monitoring systems are set up at the beginning of the implementation phase so that corresponding data can be accessed during the evaluation phase. 
As we discovered, the strategic objectives of the Bernese Nature Parks were only partially taken into account in communal, regional and cantonal planning and consultation procedures, and in sectoral policies. It would be valuable to find ways for park authorities and park management to become more involved in the ongoing development of the institutional framework (including sectoral policies) at communal, regional and cantonal levels and to be regarded as important actors in this respect.

Given the observation that park management's options for action are very limited in terms of actually fulfilling its strategic goals, it is essential to place increased focus on the strengths of the RNPs, when formulating - and communicating about - the charter. The evaluation showed that the strengths of these parks lie especially in awareness-raising and educational measures, initiation and (non-material) support of projects, motivation and networking of actors, and cooperation with actors from the local to cantonal and national level. Although difficult to quantify and qualify, such soft measures certainly promote regional change towards sustainability. They focus on changing the preconditions for action. RNPs already take on a variety of mediating and bridging functions between different actors. Park management can thus be seen - and promoted - as coordinators of regional change (see Hammer \& Siegrist 2016). However, this does not exempt park management from presenting and communicating quantifiable outputs and outcomes to ensure visibility of their direct achievements, as this is of fundamental importance for the acceptance of RNPs by local populations (Michel \& Wallner 2020).

The question arises whether the framework model can also be used for evaluations of the effects of park management activities in other countries. The answer depends in particular on the purpose of the park in question, the objectives of the evaluation, and the requirements of the authorities and any international organizations involved. However, we believe that evaluations of parks with a broad mandate in terms of sustainable development can be inspired by this model.

\section{Recommendations}

We found a degree of contradiction between the legal stipulations of the federal government and the cantons, the level of funding available and the scope of action of park management on the one hand - and, on the other, the image of RNPs as model regions of sustainable development, as postulated by the federal government and supported by social actors. In reality, the scope for RNPs to exert influence is limited. To fulfil their role as model regions, their opportunities for exerting influence at communal, regional and cantonal levels should be expanded and they should, for example, be more closely involved in policymaking.

This would require adjusting the requirements set by the government, and the scope of action of the park authorities and park management, to enable the latter to better incorporate their strategic goals into policy processes. One possibility is to expand the legal requirements of the government and the Canton of Bern. For example, RNPs could be required to show in their charters how they intend to deal with overarching demands and expectations in relation to sustainable development that are not explicitly defined by law. This would enable the evaluation to show what RNPs contribute, for example, to sustainability strategies at both communal, cantonal and national levels and globally (e.g. Sustainable Development Goals, SDGs).

However, expanding the legal requirements is also a balancing act for RNPs if their resources are not increased accordingly, their scope of influence expanded and their status as actors of regional change revalued. This requires the support of the federal government and the relevant cantons, communes, population and other local actors. RNPs in the canton of Bern - and thus also park policy - could take a step in this direction for the next ten-year operating phase, to really fulfil their role as model regions of sustainable development.

\section{Acknowledgements}

We would like to sincerely thank the reviewers and editors as well as the proofreader for their valuable feedback and suggestions for improving the manuscript. This has made the manuscript much more comprehensible. We would also like to thank the three park management teams and the other local actors involved for their close and constructive cooperation during the one and a half year evaluation process.

\section{References}

Bär, R., T. Wiesli, T. Hammer, A. Ehrensperger, K. Liechti 2020. Evaluation der Chartas der Regionalen Naturpärke Chasseral, Diemtigtal und Gantrisch. Synthesebericht im Auftrag des Amtes für Gemeinden und Raumordnung des Kantons Bern. Centre for Development and Environment (CDE) der Universität Bern. Bern. Doi: 10.7892/ boris.144132; Available at: https://boris.unibe.ch/id/ eprint/144132 (accessed: 18/03/2021)

Coad, L., F. Leverington, K. Knights, J. Geldmann, A. Eassom, V. Kapos, N. Kingston, M. de Lima, C. Zamora, I. Cuardros, C. Nolte, N.D. Burgess, M. Hockings 2015. Measuring impact of protected area management interventions: current and future use of the Global Database of Protected Area Management Effectiveness. Philosophical Transactions of The Royal Society B 370. Doi: 10.1098/rstb.2014.0281

Dinica, V. 2016. Protected Areas - How will they contribute to third millennium challenges? Policy Quarterly 12(1): 50-59.

Federal Assembly of the Swiss Confederation 1966/2020. Bundesgesetz über den Natur-und Heimatschutz. 
(NHG) vom 1. Juli 1966 (Stand am 1. April 2020). Bern.

Ferraro, P.J. \& M.M. Hanauer 2015. Through what mechanism do protected areas affect environmental and social outcomes? Philosophical Transactions of The Royal Society B 370: Doi: 10.1098/rstb.2014.0267

Ferraro, P.J. \& R.L. Pressey 2015. Measuring the difference made by conservation initiatives: protected areas and their environmental and social impacts. Philosophical Transactions of The Royal Society B 370. Doi: 10.1098/rstb.2014.0270

Ferreira, A.F., H. Zimmermann, R. Santos \& H. von Wehrden 2018. A social-ecological systems framework as a tool for understanding the effectiveness of biosphere reserve management. Sustainability 10(10). Doi: $10.3390 /$ su10103608

FOEN 2014/2019. Handbuch für die Errichtung und den Betrieb von Pärken von nationaler Bedeutung. Updated version 2019. Umwelt-Vollzug Nr. 1414 des Bundesamts für Umwelt (BAFU). Bern.

Hammer, T., I. Mose, D. Siegrist \& N. Weixlbaumer (eds.) 2016. Parks of the Future. Protected Areas in Europe Challenging Regional and Global Change. Munich.

Hammer, T. \& D. Siegrist 2016. Regional change management and collaborative regional governance as approaches tackling regional and global change in parks? Lessons learned from the Swiss model of parks of national significance. In: Hammer, T. et al. (eds.), Parks of the Future. Protected Areas in Europe Challenging Regional and Global Change: 85-100. Munich.

Hammer, T., I. Mose, D. Siegrist \& N. Weixlbaumer 2018. Großschutzgebiete in Europa im Wandel - Herausforderungen und Perspektiven für die Schutzgebietsentwicklung. Natur und Landschaft 93(5): 224-231.

Hockings, M., S. Stolton, F. Leverington, N. Dudley \& J. Courrau 2006. Evaluating Effectiveness. A framework for assessing management effectiveness of protected areas. $2^{\text {nd }}$ Edition. Gland.

Hockings, M., F. Leverington \& C. Cook 2015. Protected Area Management Effectiveness. In: Worboys, G.L., M. Lockwood, A. Kothari, S. Feary, I. Pulsford (eds.), Protected Area Governance and Management: 889928. Canberra.

Leverington, F., K.L. Costa, H. Pavese, A. Lisle \& M. Hockings 2010a. A global analysis of protected area management effectiveness. Environmental Management 46: 685-698.

Leverington, F., A. Kettner, C. Nolte, M. Marr, S. Stolton, H. Pavese, S. Stoll-Kleemann \& M. Hockings 2010b. Protected Area Management Effectiveness Assessments in Europa. Part II: Supplementary Report: Overview of European methodologies. BfN-Skripten 271b. Bonn.

Leverington, F., K. Lemos Costa, J. Courrau, H. Pavese, C. Nolte, M. Marr, L. Coad, N. Burgess, B. Bomhard \& M. Hockings 2010c. Management effectiveness evaluation in protected areas - a global study ( $2^{\text {nd }}$ edition 2010). Brisbane.
Michel, A.H \& A. Wallner 2020. How can local populations be won over to protected areas? Swiss Academies Factsheet 15(5). Bern.

Nolte, C., F. Leverington, A. Kettner, M. Marr, G. Nielsen, B. Bomhard, S. Stolton, S. Stoll-Kleemann \& M. Hockings 2010. Protected Area Management Effectiveness Assessments in Europe. A review of application, methods and results. BfN-Skripten 271a. Bonn.

Oldekop, J.A., G. Holmes, W.E. Harris \& K.L. Evans 2015. A global assessment of the social und conservation outcomes of protected areas. Conservation Biology 30(1): 133-141.

Plachter, H., U. Hampicke, L. Kruse-Graumann \& A. Kowatsch 2012. Integratives Monitoring für deutsche Grossschutzgebiete. Natur und Landschaft 87(1): 2-10.

Romagosa, F., P.F.J. Eagles \& C.J. Lemieux 2015. From the inside out to the outside in: Exploring the role of parks and protected areas as providers of human health and well-being. Journal of Outdoor Recreation and Tourism 10: 70-77.

Swiss Federal Council 2007/2018. Verordnung über die Pärke von nationaler Bedeutung (PäV) vom 7. November 2007 (Stand am 1. April 2018). Bern.

Swiss Parks Network 2021. Legal basis of Swiss parks: Acts and ordinances. Available at: https://www.parks. swiss/en/the_swiss_parks/what_is_a_park/legal_basis.php (accessed 19/02/2021)

\section{Authors}

\section{Thomas Hammer}

is Professor for Sustainable Regional and Landscape Development, Head of Study Programmes in Sustainable Development and Chair of Programme Management for the CAS in Sustainable Development at the Centre for Development and Environment (CDE) of the University of Bern. E-mail: thomas. hammer@unibe.ch https://www.cde.unibe.ch/ about_us/personen/prof_dr_hammer_thomas/

\section{Roger Bär ${ }^{1}$}

is Senior Research Scientist in the Just Economies and Human Well-Being impact area at the Centre for Development and Environment (CDE) of the University of Bern. His work focuses on sustainability research and monitoring in peri-urban and rural areas. E-mail: roger.baer@unibe.ch. https://www.cde.unibe. ch/about_us/personen/dr_baer_roger/

\section{Albrecht Ehrensperger}

is Senior Research Scientist and Head of the Sustainable Land Systems impact area at the Centre for Development and Environment (CDE) of the University of Bern. E-mail: albrecht.ehrensperger@unibe. ch. https://www.cde.unibe.ch/about_us/personen/ dr_ehrensperger_albrecht/ 


\section{Andreas Friedli}

is an economist and project manager for the Parks of National Importance and the UNESCO World Heritage Sites at the Canton of Bern, which commissioned the evaluation. He was head of the advisory group for the evaluation. Office for Communes and Land Management, Canton of Bern, Nydeggasse 11/13, 3011 Bern, Switzerland. E-mail: andreas.friedli1@be.ch. https://www.jgk.be.ch/jgk/ $\mathrm{de} /$ index/raumplanung/raumplanung/kantonale_ raumplanung/paerke.html

\section{Karina Liechti ${ }^{1}$}

is a human geographer and works at the University of Bern and at the Swiss Foundation for Landscape Conservation. Her main research focuses are commons and societal transformation processes. E-mail: karina.liechti@unibe.ch..https://www.cde.unibe.ch/ ueber_uns/personen/dr_liechti_karina/

\section{Astrid Wallner}

is a social anthropologist and works as Associated Senior Research Scientist at the Centre for Develop- ment and Environment (CDE) of the University of Bern. From 2009 to 2021 she was responsible for research on protected areas (Parks of National Importance) in Switzerland at the Forum Landscape, Alps, Parks at the Swiss Academy of Sciences. E-mail: astrid.wallner@unibe.ch

\section{Thea Xenia Wiesli ${ }^{1}$}

is a Research Associate and $\mathrm{PhD}$ candidate at the Centre for Development and Environment (CDE) and the Institute of Sociology, University of Bern. Her main research focus is on sustainable quality of life, which she investigates in rural and protected areas. E-mail: thea.wiesli@unibe.ch.https://www.cde.unibe. ch/about_us/personen/wiesli_thea_xenia/

${ }^{1}$ Centre for Development and Environment (CDE), University of Bern, Mittelstrasse 43, 3012 Bern, Switzerland 